\title{
Preparation and Coagulation Behavior of a Novel Multiple Flocculant Based on Cationic Polymer, Hydroxy Aluminum, and Clay Minerals
}

\author{
Feng-shan Zhou, Xi Wang, Lin Zhou, and Yang Liu \\ School of Materials Science and Technology, China University of Geosciences, Beijing 100083, China \\ Correspondence should be addressed to Feng-shan Zhou; zhoufs@cugb.edu.cn
}

Received 12 July 2014; Revised 22 August 2014; Accepted 22 August 2014

Academic Editor: Zhaohui Li

Copyright @ 2015 Feng-shan Zhou et al. This is an open access article distributed under the Creative Commons Attribution License, which permits unrestricted use, distribution, and reproduction in any medium, provided the original work is properly cited.

Cationic polymer, hydroxy aluminum, and clay minerals are three flocculants with different action mechanisms and a more costefficient multiple flocculant can be prepared by compositing them through appropriate technology. All of attapulgite (ATP), clay minerals containing magnesium, aluminum, and silicate, are porous environmental mineral material with good absorbability and have found wide applications in industrial sewage treatment. With polyaluminum chloride (PAC), poly(dimethyl diallyl ammonium chloride) (PDMDAAC), and attapulgite (ATP) clay being the main raw materials, multiple flocculant CMHa (liquid) with good storage stability was prepared and its optimized blending mass percent was PDMDAAC of 2\%-3\%, ATP of 4\%-6\%, and PAC of 20\%-30\%. The liquid poly(dimethyl diallyl ammonium chloride) (PDMDAAC) was firstly loaded on solid material in kneader and then mixed in certain proportion with PAC and ATP to prepare solid CMHa convenient for storage and transportation. The optimized mass ratio is PAC: ATP : PDMDAAC $=80: 10: 2.4$. When this multiple flocculant was used to treat domestic sewage, coal washing sewage, dyeing wastewater, and papermaking wastewater, its equivalent dosage was just $50 \%$ of PAC, while overall production cost has been reduced to about $40 \%$, viewing showing broad application prospect.

\section{Introduction}

Flocculants have found wide application due to their good coagulation and purification behavior, low price, and convenience and have been the most widely used water treatment agent with the largest consumption $[1,2]$.

Micromolecular inorganic salt flocculants, for example, aluminium chloride $\left(\mathrm{AlCl}_{3} \cdot 6 \mathrm{H}_{2} \mathrm{O}\right)$, ferrous sulfate $\left(\mathrm{FeSO}_{4} \cdot 7 \mathrm{H}_{2} \mathrm{O}\right)$, and ferric chloride $\left(\mathrm{FeCl}_{3} \cdot \mathrm{H}_{2} \mathrm{O}\right)$, have advantage in low cost but their alum grains are small and are strongly corrosive, so they are generally replaced by inorganic polymer flocculants. Polyaluminum chloride (PAC), polyferric sulfate (PFS), polyferric chloride (PFC), and polyaluminium ferric chloride (PAFC) are popular inorganic polymer flocculants. Relatively speaking, inorganic polymer flocculants have better flocculation performance and cheaper than organic flocculants; however their storage stability is poor and will produce plenty of sludge; thus it is difficult for subsequent treatment $[1,3]$.

Organic flocculants have advantage in low dosage, fast flocculation velocity, being affected little by coexisting salts, $\mathrm{pH}$ of medium, and environment temperature, small amount of sludge, and good decolorization performance, but they are costly and their hydrolyzed or degraded products are toxic. Organic polymer flocculant is classified as natural and multiple $[3,4]$.

Multiple flocculants can be classified as inorganic-organic multiple, organic-organic multiple, inorganic-inorganic multiple, multinuclear inorganic polymer flocculant, and so forth. Among them, multiple of polymeric aluminum, polymeric iron, and polyacrylamide is the most popular, which integrates the merits of inorganic and organic flocculants 
and makes good use of electrical neutralization, adsorption, bridging, and furl mechanism, thus improving flocculation performance, reducing costs, decreasing flocculant dosage and the amount of sludge, promoting the stability of multiple flocculant, and broadening its application. Consequently, it has been the research focus in developing new flocculant [513].

Mineral flocculants remove organics and metal ions in water through adsorption and thus no secondary contamination exists, particularly suitable for the treatment of seriously polluted domestic and industrial sewage [7, 10, 11, 13, 14]. However, mineral flocculants also have some disadvantages in practical application. At first, the dosage is large. When treating the same water sample, dosage of mineral flocculants is far larger than that of conventional flocculants (e.g., PAC). In addition, the large dosage makes larger amount of alum grain sediments after treatment than that produced by conventional flocculants. Thirdly, its treatment efficiency is low. Conventional flocculants can flocculate rapidly, while mineral flocculants remove organics and metal ions in water through adsorption and adsorption often takes some time, thus making the treatment efficiency of mineral flocculants lower.

By combining structural features and flocculation performance of organic cationic polymer $(\mathrm{C})$, inorganic hydroxy aluminium ( $\mathrm{Ha})$, and clay mineral $(\mathrm{M})$, this paper aims at developing a multiple flocculant $\mathrm{CMHa}$ with good performance and low cost.

\section{Materials and Methods}

2.1. Instruments. SGE-2 Digital Turbidity Meter (Shanghai Yuefeng Instruments Co., Ltd.), TDL-5A High-Speed Centrifuge (Shanghai Fulgor Analysis Instruments Co., Ltd.), and NH-1 Kneader (Shandong Laizhou Longhe Chemical Industrial Equipment Co., Ltd.) are used.

2.2. Materials. Attapulgite (ATP) (Mingguang, Anhui); bentonite (Ningcheng, Inner Mongolia); polyaluminum chloride (PAC) (liquid sample PAC; solid sample SPAC) (Gongyi, Henan); kaolinite (Karamay, Xinjiang); poly(dimethyl diallyl ammonium chloride) (PDMDAAC) (Kemira, Jiangsu); cationic polyacrylamide (CPAM) (Xitao, Beijing); poly(dimethyl diallyl ammonium chloride-acrylamide) (PDA) (Kemira, Jiangsu); diatomite (Linjiang, Jilin); cellulose graft starch (PPS) (Pinggu, Beijing); puffing modified starch (EPPS) (Pinggu, Beijing); and silane graft starch membrane-forming agent (SIM) (Pinggu, Beijing) are used. All of the samples are industrial products obtained from China chemical market.

\subsection{Methods}

2.3.1. Hydration of Mineral Material. Prepare suspension of clay minerals with various concentrations and then the prepared suspension was stirred for $20 \mathrm{~min}$ in high speed stirrer (10000 rpm) followed by hydrating for $16 \mathrm{~h}$.
2.3.2. Preparation of Liquid CMHa. Blend PAC, cationic polymer, and hydrated mineral suspension in various proportions at first and then the mixture was stirred at certain temperature to form uniform solution, that is, liquid $\mathrm{CMHa}$ sample.

2.3.3. Load and Solidification of PDMDAAC. Add some support materials into kneader and then add liquid PDMDAAC sample slowly. Keep heating and kneading until water in PDMDAAC evaporates almost completely; then take out the sample for crushing, that is, solidified PDMDAAC sample, recorded as PDMDAAC-S.

2.3.4. Preparation of Solid CMHa. Mix dry solid PAC, PDMDAAC-S, and clay mineral uniformly, that is, solid CMHa sample CMHa-S.

\subsection{Evaluations}

2.4.1. Evaluation on Flocculant Stability. Leave it stand and observe its stability. And then evaluate its stability by mechanical centrifugation. Take some prepared samples and centrifuge them for $5 \mathrm{~min}$ at rotation speed of $2000 \mathrm{rpm}$, $3000 \mathrm{rpm}, 4000 \mathrm{rpm}$, and $5000 \mathrm{rpm}$, respectively. The rotation speed at which sample begins separating out water or layering is selected as stability evaluation indicator. The faster rotation speed indicates better stability.

2.4.2. Evaluation on Flocculation Performances. Diatomite suspension with turbidity of 1000 NTU was prepared to simulate water sample ( $600 \mathrm{~g}$ water mixed with $1.1 \mathrm{~g}$ diatomite). Then add certain amount of flocculant sample into $100 \mathrm{~mL}$ simulated water sample and stir rapidly for $2 \mathrm{~min}$ at first and then stir slowly for another 2 min. After that, add certain amount of polyacrylamide and stir slowly for $2 \mathrm{~min}$. Observe and record the size and settling time of alum grain. After $30 \mathrm{~min}$, measure the turbidity of supernatant.

\section{Results and Discussion}

\subsection{Influence Factors on Stability and Coagulation Behavior of $\mathrm{CMHa}$}

3.1.1. Mineral Materials Types. It can be known through investigating the stability of CMHa prepared by different mineral materials (shown in Table 1) that the presence of bentonite in ternary system makes the system layer and yellow liquid separate out in upper layer; precipitates can be observed in the system in the presence of kaolinite as kaolinite tends not to suspend; ATP makes the ternary system very stable, so it is selected as mineral material used in following tests.

3.1.2. Cationic Polymers. The presence of PDA makes CMHa ternary system layer, while adding PDMDAAC will not affect the system's stability. However, if content of PDMDAAC exceeds $3 \%$, viscosity of the system will increase and thus it cannot flow easily after standing, while low content will 
TABLE 1: The stability of different kinds of minerals in the CMHa.

\begin{tabular}{|c|c|c|c|c|c|}
\hline \multirow[b]{2}{*}{ PAC } & \multicolumn{3}{|c|}{ СMHa (\%) } & \multirow[b]{2}{*}{ ATP } & \multirow{2}{*}{ Sample appearance after standing } \\
\hline & PDMDAAC & Bentonite & Kaolinite & & \\
\hline 15 & 1 & & 15 & & Settling \\
\hline 15 & 2 & & 10 & & Settling \\
\hline 20 & 1 & 4.0 & & & Obvious separated layer \\
\hline 20 & 1 & 5.0 & & & Obvious separated layer \\
\hline 25 & 1 & 5.0 & & & Obvious separated layer \\
\hline 15 & 1 & 5.0 & 5.0 & & Separated layer \\
\hline 15 & 1 & 3.0 & 3.0 & 3.0 & Separated layer \\
\hline 15 & 1 & & & 5.0 & Stable \\
\hline 15 & 1 & & 6.0 & 4.0 & Settling \\
\hline 15 & 1 & 3.5 & 1.5 & & Separated layer \\
\hline
\end{tabular}

TABLE 2: The influence of different kinds of cationic polymers on the stability of CMHa.

\begin{tabular}{|c|c|c|c|c|}
\hline \multirow[b]{2}{*}{ PAC } & \multicolumn{2}{|c|}{$\mathrm{CMHa}(\%)$} & \multirow[b]{2}{*}{ ATP } & \multirow{2}{*}{ Sample appearance after standing } \\
\hline & PDMDAAC & PDA & & \\
\hline 20 & 1 & & 5 & Relatively stable \\
\hline 20 & 2 & & 5 & Relatively stable \\
\hline 20 & 3 & & 5 & Thick and viscous \\
\hline 20 & & 1 & 5 & Obvious separated layer \\
\hline 20 & & 2 & 5 & Obvious separated layer \\
\hline 20 & & 3 & 5 & Obvious separated layer \\
\hline
\end{tabular}

TABLE 3: The influence of attapulgite on the stability of CMHa.

\begin{tabular}{|c|c|c|c|}
\hline \multicolumn{3}{|c|}{ СMHa (\%) } & \multirow{2}{*}{ Sample appearance after standing } \\
\hline PAC & PDMDAAC & ATP & \\
\hline 25 & 2 & 3.7 & $\begin{array}{c}\text { A little water separated in the } \\
\text { upper part }\end{array}$ \\
\hline 25 & 2 & 4.2 & Uniform \\
\hline 25 & 2 & 4.8 & Uniform \\
\hline 25 & 2 & 5.2 & Uniform \\
\hline 25 & 2 & 5.5 & Uniform \\
\hline 25 & 2 & 6.0 & Difficult to flow \\
\hline 25 & 2 & 7.0 & Difficult to flow \\
\hline
\end{tabular}

degrade the flocculation performance of products. Consequently, the suitable dosage of PDMDAAC is $2 \%-3 \%$, as shown in Table 2.

3.1.3. Mineral Material Content. When content of ATP was lower than $4 \%$, viscosity of product is low and water tends to separate out in upper layer, and thus layering is observed; while content of ATP is greater than $6 \%$, viscosity of product is too high and its flow ability becomes poor after standing. Consequently, appropriate content of ATP ranges from $4 \%$ to $6 \%$, as seen in Table 3 .

3.1.4. Reaction Temperature. Influence of reaction temperature on stability, viscosity, and flocculation behavior can be seen in Tables 4 and 5. Increasing temperature promotes stability, increases viscosity of system, and enhances flocculation performance. However, solidification will be observed after standing some time due to high viscosity and poor flow ability. Therefore, optimal temperature should be $40^{\circ} \mathrm{C} \sim 60^{\circ} \mathrm{C}$.

3.1.5. Polyaluminum Chloride (PAC). PAC exerts great influence on the stability and flocculation behavior of $\mathrm{CMHa}$. Results in Table 6 show that PAC content of 35\% makes the flow ability of product poor. Content of PAC affects the performance of multiple flocculant directly and it should be as high as possible if stability allows for it. Therefore, the optimal content of PAC should be $25 \% \sim 30 \%$.

3.2. Effects of Treating Water with Different Turbidities Used Liquid CMHa. Compare the flocculation performance of solid PAC (SPAC) with that of liquid CMHa sample prepared at $60^{\circ} \mathrm{C}$ in the selected optimal blending ratio with good stability (25\% PAC + 2\% PDMDAAC + 5\% ATP) according to results in Table 6 . Results in Table 7 show that, when compounding with CPAM, turbidity removal performance of liquid CMHa with two times of dosage was better than that of solid PAC and settling velocity also accelerates. When singly used, turbidity removal performance of liquid CMHa with two times of dosage was improved significantly and settling velocity also accelerated considerably.

\subsection{Solidification of $\mathrm{CMHa}$}

3.3.1. Selecting Carrier for PDMDAAC. To address the inconvenient storage and transportation of liquid $\mathrm{CMHa}$, porous 
TABLE 4: The influence of reaction temperature on the stability and the coagulation behavior for the produced samples (1000 NTU diatomite suspension).

\begin{tabular}{|c|c|c|c|c|c|}
\hline PAC & $\begin{array}{r}\text { CMHa (\%) } \\
\text { PDMDAAC }\end{array}$ & ATP & Reaction temperature $\left({ }^{\circ} \mathrm{C}\right)$ & Centrifugal stability (rpm) & Residual turbidity (NTU) \\
\hline 25 & 2 & 5 & 25 & 3000 & 1.1 \\
\hline 25 & 2 & 5 & 40 & 3000 & 0.80 \\
\hline 25 & 2 & 5 & 60 & 4000 & 0.63 \\
\hline 25 & 2 & 5 & 80 & 5000 & 0.42 \\
\hline
\end{tabular}

TABLE 5: The influence of reaction temperature on the appearance viscosity of produced samples.

\begin{tabular}{lcccc}
\hline PAC & $\begin{array}{c}\text { CMHa (\%) } \\
\text { PDMDAAC }\end{array}$ & RTP & Reaction temperature $\left({ }^{\circ} \mathrm{C}\right)$ & Thin liquid \\
\hline 20 & 3 & 6 & 40 & Thick liquid \\
20 & 3 & 6 & 60 & Difficult to flow \\
20 & 3 & 6 & 80 & Thin liquid \\
25 & 2 & 6 & 60 & Viscous liquid \\
25 & 2 & 6 & 80 & Difficult to flow \\
25 & 2 & 6 & 60 & . \\
\hline
\end{tabular}

TABLE 6: The influence of PAC in CMHa on the stability of produced flocculants.

\begin{tabular}{lcccc}
\hline CMHa (\%) & Reaction temperature $\left({ }^{\circ} \mathrm{C}\right)$ & Centrifugal stability (rpm) \\
PAC & PDMAAC & 5 & 60 & 3000 \\
15 & 2 & 5 & 60 & 3000 \\
20 & 2 & 5 & 60 & 4000 \\
30 & 2 & 5 & 60 & 4000 \\
35 & 2 & 5 & 60 & Difficult to flow \\
\hline
\end{tabular}

solid materials are used to carry PDMDAAC solution with active ingredient content of $40 \%$ at first. Then compounding with solid PAC and solid CPAM, solid CMHa can be prepared, that is, CMHa-S. Solid carriers used in tests as shown in Table 8 were selected from natural mineral materials (Attapulgite, Diatomite, Kaolinite, Bentonite) and natural polymeric materials (PPS, EPPS, and SIM). Flocculation performance of SPAC and CMHa-S sample with optimal blending ratio was compared, as seen in Table 9. By comparing the capacity of carriers, status being loaded by PDMDAAC, flocculation performance, and costs, SIM was finally selected as the carrier for liquid PDMDAAC. CMHa-S sample prepared by SIM being as carrier is the best option.

3.3.2. Comparing Flocculent Performance of CMHa with Different PDMDAAC Contents. CMHa samples with different PDMDAAC contents were prepared as seen in Table 10. These samples were used to treat diatomite suspension of $1000 \mathrm{NTU}$ to compare their flocculation performance and results shown in Table 11. Results show that higher PDMDAAC content meant better flocculation performance of $\mathrm{CMHa}$ in the presence/absence of CPAM. Coagulation behavior of CMHaS-PDMDAAC24 sample in the absence of CPAM was similar to that of SPAC with three times higher dosage than it and the settling velocity accelerates considerably, while its flocculation performance in the presence of CPAM was similar to that of SPAC with two times higher dosage than it. It is suggest that SPAC mixed mineral material and cationic polymer with an enhanced coagulation performance. However, increasing PDMDAAC content in samples made kneading difficult, so CMHa-S-PDMDAAC24 was an optimized formula considering both cost efficiency and technology.

3.3.3. Economic Efficiency of CMHa-S. Taking CMHa-SPDMDAAC24 as an example and according to current price of raw materials, it can be known that total cost of raw materials is 2100 yuan/ton, comprehensive processing charge is 300 yuan/ton, total production cost is 2400 yuan/ton, and selling price is 3000 yuan/ton. As the equivalent dosage of SPAC is 2 3 times higher than that of CMHa-S and the price of good SPAC is about 2500 yuan/ton, the price of CMHa-S is only $40 \%$ lower than that of PAC. And therefore CMHa-S is more cost-efficient.

3.4. Results of CMHa Treating Industrial Sewage. The industrial solid CMHa-S-PDMDAAC24 sample was diluted by water to $32 \%$ and then the solution was used to treat domestic sewage, coal washing sewage, and dyeing wastewater. Then 
TABLE 7: The coagulation behaviors of CMHa versus PAC (100-1000 NTU diatomite suspension).

\begin{tabular}{lccccc}
\hline $\begin{array}{l}\text { Turbidity of } \\
\text { diatomite } \\
\text { suspension (NTU) }\end{array}$ & Flocculants (mg/L) & CPAM (mg/L) & Settling time (s) & $\begin{array}{c}\text { Residual turbidity } \\
\text { (NTU) }\end{array}$ & Coagulation behaviors \\
\hline 1000 & SPAC (30) & 3 & 50 & 5.7 & Larger alum floc \\
1000 & CMHa (60) & 3 & 40 & 4.5 & Larger alum floc \\
1000 & SPAC (60) & - & 130 & 7.6 & Larger alum floc \\
1000 & CMHa (120) & - & 90 & 6.9 & Larger alum floc \\
\hline 500 & SPAC (20) & 2 & 50 & 2.3 & Larger alum floc \\
500 & CMHa (40) & 2 & 150 & 4.5 & Larger alum floc \\
500 & SPAC (40) & - & 100 & 3.1 & Smaller alum floc \\
500 & CMHa (80) & - & 80 & 1.8 & Larger alum floc \\
\hline 100 & SPAC (15) & 2 & 70 & 1.6 & Larger alum floc \\
100 & CMHa (30) & 2 & 180 & 2.5 & Larger alum floc \\
100 & SPAC (30) & - & 120 & Smaller alum floc & Larger alum floc \\
100 & CMHa (60) & - & 5.9 &
\end{tabular}

TABLE 8: The carried dosage of different carrier materials for PDMDAAC.

\begin{tabular}{lccc}
\hline Carrier materials (g) & PDMDAAC (g) & $\begin{array}{c}\text { Content of PDMDAAC in } \\
\text { solidified samples (\%) }\end{array}$ & Characteristics of solidified samples \\
\hline Attapulgite (100) & 100 & 28.6 & High viscosity and difficulty to kneading reaction \\
Bentonite (100) & 100 & 28.6 & High viscosity and difficulty to kneading reaction \\
Diatomite (100) & 200 & 44.4 & Low viscosity and easiness to kneading reaction \\
EPPS (100) & 80 & 24.0 & High viscosity and difficulty to kneading reaction \\
PPS (100) & 80 & 24.0 & Low viscosity and easiness to kneading reaction \\
SIM (100) & 80 & 24.0 & Low viscosity and easiness to kneading reaction \\
\hline
\end{tabular}

TABLE 9: The influence of different carrier materials on the coagulation behaviors of CMHa-S (1000 NTU diatomite suspension).

\begin{tabular}{lccc}
\hline Flocculants (mg/L) & $\begin{array}{c}\text { CPAM } \\
(\mathrm{mg} / \mathrm{L})\end{array}$ & $\begin{array}{c}\text { Settling } \\
\text { time }(\mathrm{s})\end{array}$ & $\begin{array}{c}\text { Residual } \\
\text { turbidity (NTU) }\end{array}$ \\
\hline SPAC (30) & 2 & 20 & 0.9 \\
SPAC (45) & 2 & 20 & 0.6 \\
CMHa-S-SIM (15) & 2 & 20 & 0.8 \\
CMHa-S-diatomite (15) & 2 & 30 & 1.5 \\
CMHa-S-PPS (15) & 2 & 25 & 1.3 \\
\hline SPAC (100) & & 150 & 5.5 \\
SPAC (150) & & 90 & 2.5 \\
CMHa-S-SIM (50) & & 90 & 2.4 \\
CMHa-S- diatomite (50) & & 100 & 2.6 \\
CMHa-S-PPS (50) & & 110 & 3.7 \\
\hline
\end{tabular}

evaluate its flocculation performance and compare with that of SPAC.

3.4.1. Treating Domestic Sewage. Results in Table 12 show that when CMHa was used to treat the domestic sewage of a sewage treatment plant in Changzhou the residual turbidity of treated water is lower than that treated by PAC, and alum
TABLE 10: CMHa-S with different carried dosage of PDMDAAC.

\begin{tabular}{lcccc}
\hline \multirow{2}{*}{ Samples number } & \multicolumn{4}{c}{ CMHa (\%) } \\
& SPAC & ATP & SIM & PDMDAAC \\
\hline CMHa-S-PDMDAAC8 & 80 & 10 & 9.2 & 0.8 \\
CMHa-S-PDMDAAC16 & 80 & 10 & 8.4 & 1.6 \\
CMHa-S-PDMDAAC24 & 80 & 10 & 7.6 & 2.4 \\
\hline
\end{tabular}

grain produced by CMHa is larger and its settling velocity is faster.

3.4.2. Treating Dyeing Wastewater. Flocculation behaviors of CMHa versus PAC for treating dyeing wastewater of a textile dyeing and printing plant in Shandong were shown in Table 13. The original wastewater with turbidity of 52 NTU is neutral $\mathrm{pH}$ and looks light yellow. Turbidity removal performance of CMHa with only half dosage of PAC can approach that of PAC, while settling velocity of CMHa is faster than that of PAC and its floccules were larger.

3.4.3. Treating Papermaking Wastewater. Flocculation behaviors of CMHa versus PAC for treating papermaking wastewater of a paper mill in Zhejiang were shown in Table 14. Being used singly, the turbidity removal performance and settling velocity of CMHa and PAC are close to each other. However, 
TABLE 11: The coagulation behaviors of CMHa-S carried different dosage of PDMDAAC (1000 NTU diatomite suspension).

\begin{tabular}{|c|c|c|c|c|}
\hline Dosage of flocculants (mg/L) & $\mathrm{CPAM}(\mathrm{mg} / \mathrm{L})$ & Settling time (s) & $\begin{array}{c}\text { Residual } \\
\text { turbidity (NTU) }\end{array}$ & $\begin{array}{l}\text { Characteristics of alum floc } \\
\text { during coagulation reaction }\end{array}$ \\
\hline SPAC (100) & & 150 & 5.5 & Alum floc slow and minor \\
\hline SPAC (150) & & 100 & 2.2 & Alum floc quick and larger \\
\hline CMHa-S-PDMDAAC8 (50) & & 100 & 4.5 & Alum floc quick and larger \\
\hline CMHa-S-PDMDAAC16 (50) & & 90 & 3.1 & Alum floc quick and larger \\
\hline CMHa-S-PDMDAAC24 (50) & & 80 & 2.1 & Alum floc quick and larger \\
\hline SPAC (30) & 2 & 20 & 1.4 & Alum floc quick and larger \\
\hline CMHa-S-PDMDAAC8 (15) & 2 & 20 & 1.2 & Alum floc quick and larger \\
\hline CMHa-S-PDMDAAC16 (15) & 2 & 25 & 1.1 & Alum floc quick and larger \\
\hline CMHa-S-PDMDAAC24 (15) & 2 & 20 & 0.8 & Alum floc quick and larger \\
\hline
\end{tabular}

TABLE 12: Coagulation behaviors of CMHa versus PAC for domestic-sewage treatment (original wastewater 50 NTU).

\begin{tabular}{lcccc}
\hline Dosage of flocculants $(\mathrm{mg} / \mathrm{L})$ & CPAM $(\mathrm{mg} / \mathrm{L})$ & Settling time $(\mathrm{s})$ & Residual turbidity (NTU) & Coagulation behaviors \\
\hline SPAC (20) & 5 & 80 & 2.7 & Smaller alum floc \\
CMHa (10) & 5 & 70 & 2.3 & Larger alum floc \\
SPAC (30) & 5 & 70 & 1.4 & Larger alum floc \\
CMHa (15) & 5 & 70 & 1.1 & Larger alum floc \\
\hline SPAC (20) & & 300 & 5.8 & Smaller alum floc \\
CMHa (10) & & 200 & 5.6 & Smaller alum floc \\
CMHa (20) & 180 & 4.6 & Larger alum floc \\
\hline
\end{tabular}

TABLE 13: Coagulation behaviors of CMHa versus PAC for dyeing-wastewater treatment (original wastewater $52 \mathrm{NTU}$ ).

\begin{tabular}{lcccc}
\hline Dosage of flocculants $(\mathrm{mg} / \mathrm{L})$ & CPAM $(\mathrm{mg} / \mathrm{L})$ & Settling time $(\mathrm{s})$ & Residual turbidity (NTU) & Coagulation behaviors \\
\hline SPAC (200) & 10 & 120 & 20.2 & Smaller alum floc \\
CMHa (100) & 10 & 100 & 20.5 & Smaller alum floc \\
SPAC (400) & 10 & 100 & 10.3 & Smaller alum floc \\
CMHa (200) & 10 & 80 & 10.8 & Larger alum floc \\
Solid PFS (400) & 10 & - & - & Without effect \\
Solid $\mathrm{FeSO}_{4}(400)$ & 10 & - & - & Without effect \\
\hline
\end{tabular}

TABLE 14: Coagulation behaviors of CMHa versus PAC for paper-making wastewater treatment (original wastewater 850 NTU).

\begin{tabular}{lcccc}
\hline Dosage of flocculants $(\mathrm{mg} / \mathrm{L})$ & CPAM $(\mathrm{mg} / \mathrm{L})$ & Settling time $(\mathrm{s})$ & Residual turbidity (NTU) & Coagulation behaviors \\
\hline SPAC (100) & 3 & 50 & 50 & Smaller alum floc \\
SPAC (120) & 3 & 40 & 42 & Larger alum floc \\
CMHa (50) & 3 & 50 & 65 & Larger alum floc \\
CMHa (100) & 3 & 40 & 52 & Larger alum floc \\
\hline SPAC (200) & & 70 & 43 & Smaller alum floc \\
SPAC (250) & 60 & 40 & Larger alum floc \\
CMHa (100) & 60 & 45 & Larger alum floc \\
CMHa (150) & 60 & 42 & Larger alum floc \\
\hline
\end{tabular}

when compounding with CPAM, the settling velocity of $\mathrm{CMHa}$ is faster than that of PAC and its floccules were larger.

3.4.4. Treating Coal Washing Sewage. Flocculation behaviors of CMHa versus PAC for treating coal washing sewage of a coal washing plant in Shanxi were shown in Table 15.
Turbidity removal performance of CMHa with only half dosage of PAC is far better than that of PAC.

3.5. Action Mechanism of Multiple Flocculant. The three components of CMHa work differently. CMHa makes full use of the comprehensive characteristics of inorganic and 
TABLE 15: Coagulation behaviors of CMHa versus PAC for coal-washing wastewater treatment (original wastewater 1200 NTU).

\begin{tabular}{lcccc}
\hline Dosage of flocculants $(\mathrm{mg} / \mathrm{L})$ & CPAM $(\mathrm{mg} / \mathrm{L})$ & Settling time $(\mathrm{s})$ & Residual turbidity (NTU) & Coagulation behaviors \\
\hline SPAC (50) & 5 & 20 & 19 & Larger alum floc \\
CMHa (30) & 5 & 15 & 9.4 & Larger alum floc \\
CMHa (20) & 5 & 15 & 40 & Larger alum floc \\
\hline SPAC (80) & & 150 & 14 & Smaller alum floc \\
CMHa (50) & & 60 & 22 & Larger alum floc \\
CMHa (40) & & 80 & Larger alum floc \\
\hline
\end{tabular}

organic polymer flocculants and adsorption, bridging, and flocculation aid capacity of natural porous mineral materials, which is not simple arithmetical addition of flocculation performance of single component. Combining the previous research and results of this paper, action mechanism of multiple flocculant includes the following three aspects.

3.5.1. Role of Mineral Material in CMHa. Being as flocculant, mineral material contains exchangeable inorganic cations in its interlayer and some oxygen atoms exposed on its crystal surface. This special molecular structure and irregular crystal defect of mineral material enable it to adsorb contaminants in water well. Clay mineral is characterized as being porous, having large specific surface area, and having strong polarity and its price is often lower than that of conventional flocculants. Some unwieldy contaminants in water (e.g., organics and metal ions) can be removed through adsorption of minerals and secondary pollution can be avoided $[10,11]$.

3.5.2. Role of Hydroxyl Aluminum in CMHa. Polyaluminum chloride is an intermediate from hydrolyzation and its flocculation performance is related to its degree of alkalization. It is often expressed by the formula $\mathrm{Al}_{2}(\mathrm{OH})_{n} \mathrm{Cl}_{(6-n)}$ and $n$ means degree of alkalization. Hydroxyl aluminum contains polyhydroxy complex-ions and these ions will form multinuclear complex-ions using $\mathrm{OH}^{-}$as bridge. So it can adsorb colloidal particles strongly and then promote the agglomeration of colloid through adsorption, bridging, and cross-linking. Meanwhile, physicochemical changes will occur and then charges on the surface of colloidal particles and suspended solids can be neutralized and Zeta potential is reduced, which makes the repulsive colloid particles become attractive, destroys the stability of micelles, and promotes the collision of colloidal particles, and therefore flocculant coagulative precipitation is produced and its surface area can be as large as (200-1000) $\mathrm{m}^{2} / \mathrm{g}$, having adsorption capacity [12, 15-18]. In short, polyaluminum chloride plays various roles including adsorption, destabilization, adhesion, bridging, and furl flocculation.

3.5.3. Role of Polymer in CMHa. The molecular mass, molecular structure, shape, and groups of polymer can affect the activity of flocculant. In addition, organic flocculant carried charge and thus can play electrical neutralization. Due to its large molecular mass, polymer can be regarded as a bridge helping produce flocs with structure of "colloidal particlepolymer-colloidal particle" and the flocs will settle. It can be interpreted as that two colloidal particles with like charges are connected together by a colloidal particle with unlike charges to form precipitate. Polymer flocculant with linear structure can be absorbed on the surface of colloidal particles and can enlarge the volume of alum grains and accelerate settling through furl mechanism $[19,20]$.

\section{Conclusions}

Cationic polymer, hydroxy aluminum, and clay minerals are three flocculants with different action mechanisms and a more cost-efficient multiple flocculant can be prepared by compositing them through appropriate technology.

With polyaluminum chloride (PAC), poly(dimethyl diallyl ammonium chloride) (PDMDAAC), and attapulgite (ATP) clay being the main raw materials, multiple flocculant $\mathrm{CMHa}$ (liquid) with good storage stability was prepared and its optimized blending mass percent was PDMDAAC of $2 \%$ $3 \%$, ATP of $4 \%-6 \%$, and PAC of $20 \%-30 \%$.

The liquid poly(dimethyl diallyl ammonium chloride) (PDMDAAC) was firstly loaded on solid material in kneader and then mixed in certain proportion with PAC and ATP to prepare solid CMHa convenient for storage and transportation. The optimized mass ratio is PAC:ATP:SIM: PDMDAAC $=80: 10: 7.6: 2.4$. When this multiple flocculant was used to treat domestic sewage, coal washing sewage, dyeing wastewater, and papermaking wastewater, its equivalent dosage was just $50 \%$ of PAC, while overall production cost has been reduced about $40 \%$. Consequently, multiple flocculant CMHa shows broad application prospect.

\section{Conflict of Interests}

The authors declare that there is no conflict of interests regarding the publication of this paper.

\section{Acknowledgment}

This research was supported by National High Technology Research and Development Program of China (863 Program 2012AA06A109).

\section{References}

[1] K. E. Lee, N. Morad, T. T. Teng, and B. T. Poh, "Development, characterization and the application of hybrid materials in 
coagulation/flocculation of wastewater: a review," Chemical Engineering Journal, vol. 203, pp. 370-386, 2012.

[2] S. H. Yang, F. L. Yang, and G. H. Ai, "Advances in reseach and application of water treatment flocculant," Chemical Industry Times, vol. 20, no. 2, pp. 73-75, 2006.

[3] F. S. Zhou, S. H. Wang, J. Y. Li, and J. G. Wu, "Progress in researches of polysilicate-containing composite inorganic polymer flocculants," Oilfield Chemistry, vol. 19, no. 4, pp. 391394, 2002.

[4] A. K. Verma, R. R. Dash, and P. Bhunia, "A review on chemical coagulation/flocculation technologies for removal of colour from textile wastewaters," Journal of Environmental Management, vol. 93, no. 1, pp. 154-168, 2012.

[5] J. Xia, R. Q. Su, and X. W. He, "Water resources problems in china and their countermeasures \& suggestions," Bulletin of Chinese Academy of Sciences, vol. 23, no. 2, pp. 116-120, 2008.

[6] F. S. Zhou, S. H. Wang, J. Z. Su et al., "The infrared spectra and characteristics of PMC-a multicore inorganic polymer flocculant," Fine Chemicals, vol. 20, no. 10, pp. 615-620, 2003.

[7] Y. Yang, Synthesis and application of surface modification of attapulgite and its polymer composite flocculants, assistantcoagulate [Ph.D. dissertation], Lanzhou University, Lanzhou, China, 2007.

[8] R. R. Lu, Y. H. Zhang, F. S. Zhou, X. Wang, Q. An, and Z. Meng, "Novel polyaluminum ferric chloride composite coagulant from Bayer red mud for wastewater treatment," Desalination and Water Treatment, vol. 2013, Article ID 831791, 9 pages, 2013.

[9] M. Yan and J. Ni, "Enhanced coagulation for high alkalinity and micro-polluted water: the third way through coagulant optimization," Water Research, vol. 42, no. 8-9, pp. 2278-2286, 2008.

[10] R. Srinivasan, "Advances in application of natural clay and its composites in removal of biological, organic, and inorganic contaminants from drinking water," Advances in Materials Science and Engineering, vol. 2011, Article ID 872531, 17 pages, 2011.

[11] Y. Wang and D. F. Zeng, "Compound clay's application in watertreatment flocculants," Environmental Study and Monitoring, vol. 21, no. 4, pp. 53-54, 2008.

[12] L. Gao, Study on preparation and application of polyaluminum ferric chloride [Ph.D. thesis], Harbin University of Science \& Technology, Harbin, China, 2007.

[13] D. An, Study on the removal of algae with coagulation by polymeric aluminum chloride compounded with different size of clay [Ph.D. thesis], Qingdao University, Qingdao, China, 2008.

[14] K. L. Yeap, T. T. Teng, and B. T. Poh, "Preparation and characterization of coagulation/flocculation behavior of a novel inorganic-organic hybrid polymer for reactive and disperse dyes removal," Chemical Engineering Journal, vol. 243, pp. 305314, 2014.

[15] G. Ovejero, A. Rodríguez, A. Vallet, and J. García, "Catalytic wet air oxidation of a non-azo dye with $\mathrm{Ni} / \mathrm{MgAlO}$ catalyst," Chemical Engineering Journal, vol. 215-216, pp. 168-173, 2013.

[16] W. Y. Yang, J. W. Qian, and Z. Q. Shen, "A novel flocculant of $\mathrm{Al}(\mathrm{OH})_{3}$-polyacrylamide ionic hybrid," Journal of Colloid and Interface Science, vol. 273, no. 2, pp. 400-405, 2004.

[17] P. A. Moussas and A. I. Zouboulis, "A study on the properties and coagulation behaviour of modified inorganic polymeric coagulant-Polyferric silicate sulphate (PFSiS)," Separation and Purification Technology, vol. 63, no. 2, pp. 475-483, 2008.
[18] F. El-Gohary and A. Tawfik, "Decolorization and COD reduction of disperse and reactive dyes wastewater using chemicalcoagulation followed by sequential batch reactor (SBR) process," Desalination, vol. 249, no. 3, pp. 1159-1164, 2009.

[19] K. E. Lee, B. T. Poh, N. Morad, and T. T. Teng, "Synthesis and characterization of hydrophobically modified cationic acrylamide copolymer," International Journal of Polymer Analysis and Characterization, vol. 13, no. 2, pp. 95-107, 2008.

[20] M. Ng, A. E. Liana, S. Liu et al., "Preparation and characterisation of new-polyaluminum chloride-chitosan composite coagulant," Water Research, vol. 46, no. 15, pp. 4614-4620, 2012. 

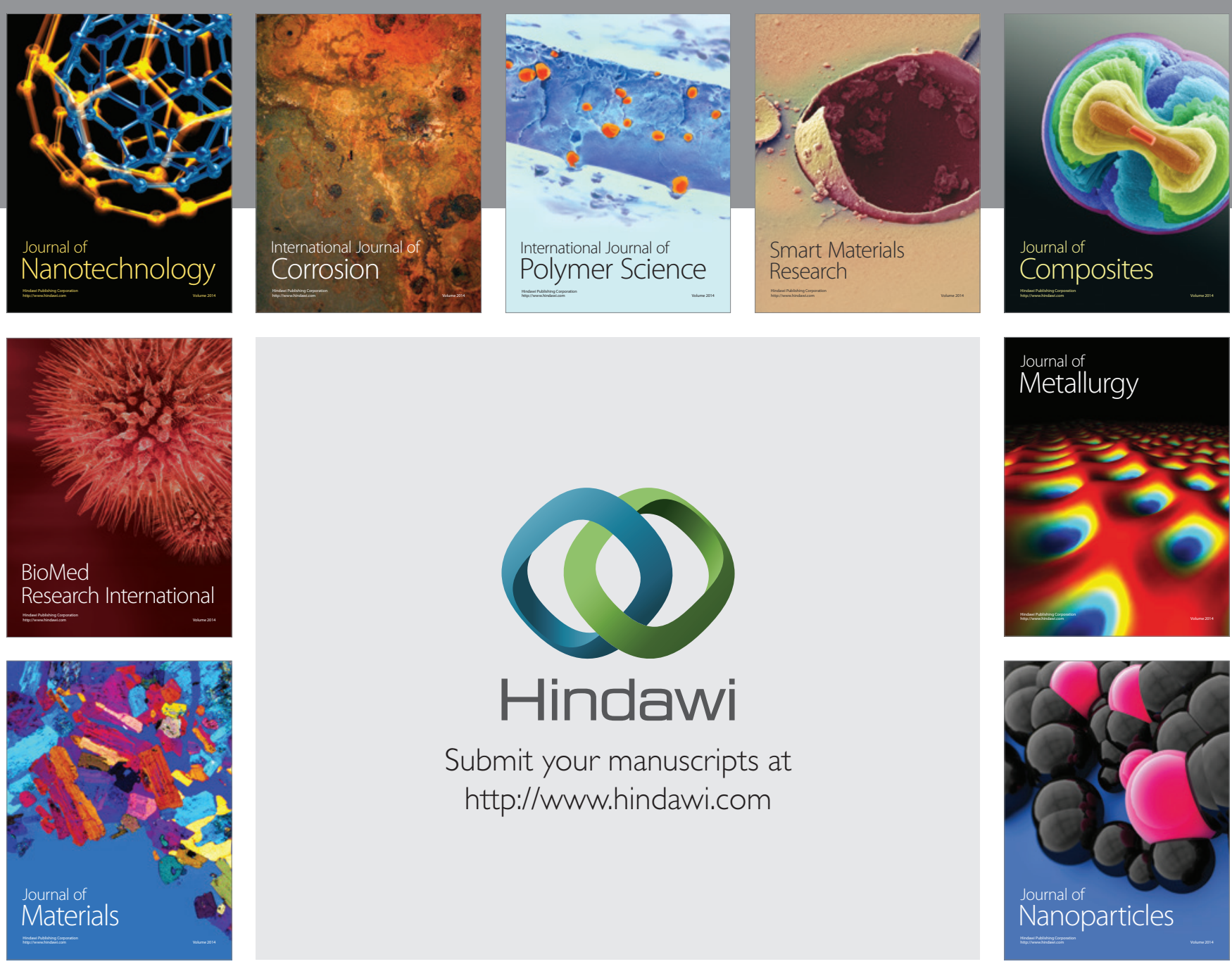

Submit your manuscripts at http://www.hindawi.com
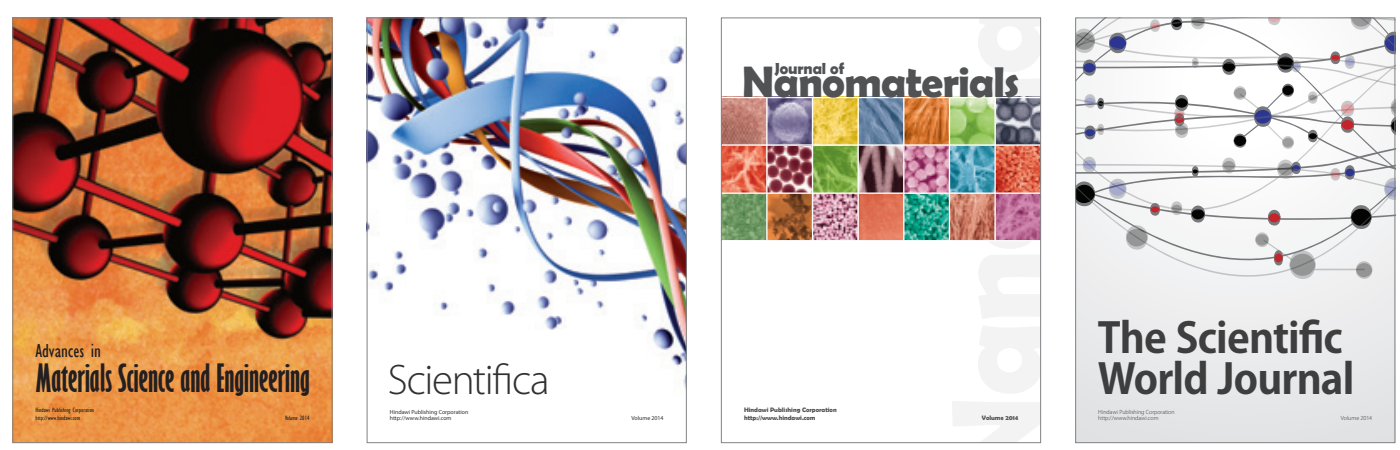

\section{The Scientific World Journal}
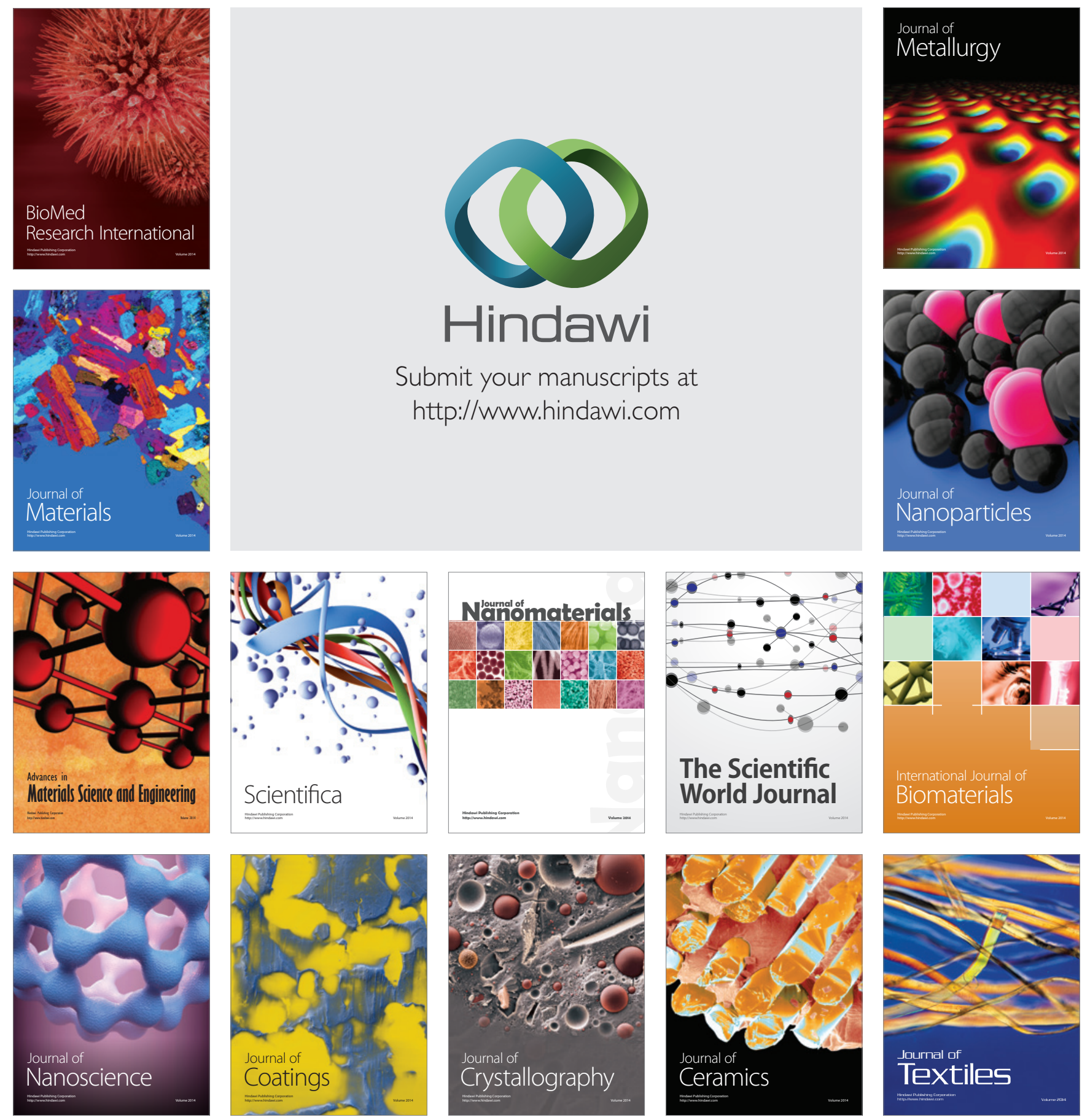